\title{
Editorial
}

\section{Regulation of Marketing of Breast milk Substitutes}

\author{
Khatoon S
}

The World Health Organization and UNICEF have emphasized the importance of maintaining the practice of breast feeding. A variety of factors influence the prevalence and duration of breastfeeding. After the World war I, with the invention of artificial milk women were liberated from the responsibilities of feeding babies; however, it lead to the wide spread malnutrition in children leading to increase in child mortality.

The $27^{\text {th }}$ World Health Assembly (WHA) in 1974 also noted the general decline in breastfeeding and increasing death of infants. This increase in child mortality was related to the production of manufactured breast-milk substitutes. Therefore WHA urged member countries to review sales promotion activities on baby foods and to introduce appropriate remedial measures, including advertisement codes and legislation. In the latter part of 1978, WHO and UNICEF decided to organize a joint a meeting on infant and young child feeding. The discussions were organized on five main themes which was included the encouragement and support of breast-feeding; the promotion and support of appropriate and timely complementary feeding practices with the use of local food resources; the strengthening of education, training and information on infant and young child feeding; the promotion of the health and social status of women in relation to infant and young child health and feeding; and the appropriate marketing and distribution of breast-milk substitutes.

In May 1980, the $33^{\text {rd }}$ World Health Assembly endorsed in their statement and recommended that "There should be an international code of marketing of infant formula and other products used as breast-milk substitutes". In May 1981 the Health Assembly debated and adopted the International Code of Marketing of Breast-milk Substitute ${ }^{1}$ to protect and promote breastfeeding, through the provision of adequate information on appropriate infant feeding and the regulation of the marketing of breast milk substitutes, bottles and teats. All governments should adopt the Code into national legislation. Since 1981, 84 countries have enacted legislation implementing all or many of the provisions of the Code and subsequent relevant World Health Assembly resolutions. In addition, 14 countries have draft laws awaiting adoption. UNICEF is working with legislators and lawyers to ensure the Code and maternity protection laws are implemented in more countries.

Governments should have the responsibility to ensure the objective and consistent information is provided on infant and young child feeding for use by families and those involved in the field of infant and young child nutrition. Informational and educational materials, dealing with the feeding of infants, should include clear information on all the following points: a the benefits and superiority of breast-feeding; maternal nutrition, and the preparation for and maintenance of breast-feeding; the negative effect on breast-feeding of introducing partial bottle-feeding; the health hazards of unnecessary or improper use of infant formula and other breast-milk substitutes.

The health authorities in member states should take appropriate measures to encourage and protect breastfeeding and promote the principles of this Code, and should give appropriate information and advice to health workers in regard to their responsibilities. No financial or material inducements to promote products within the scope of this Code should be offered by manufacturers or distributors to health workers or members of their families, nor should these be accepted by health workers or members of their families.

Governments should take action to give effect to the principles and aim of this Code, as appropriate to their social and legislative framework, including the adoption of national legislation, regulations or other suitable measures. Bangladesh government first adopted the Breast milk substitute code in 1984. But this code was weaker than the International code so a new Law was passed by parliament in September 2013. The jurisdiction of the law is now broader than previous one. This Act shall be called the Breast milk Substitutes, Infant Foods, Commercially Manufactured Complementary Foods and the Accessories Thereof (Regulation of Marketing) Act, 20132. The

Correspondence: Prof. Soofia Khatoon, Professor, Department of Paediatrics, Shaheed Suhrawardy Medical College, Sher-E-Bangla Nagar, Dhaka1207, Bangladesh; Email: soofia_icmh@yahoo.com; Cell no.:+8801911342511 
Bangladeshi Act has 24 sections describing different restrictions and directives which were included in International code of Marketing of Breast milk Substitutes.

For the purpose of import, local production, marketing, sale or distribution, no person shall print, exhibit, circulate or publish any advertisement of any breast-milk substitutes, infant foods, commercially manufactured complementary foods and any accessories. The following things particularly shall not be done, namely to distribute to any people, particularly any person or student or their family member who is engaged in or related to health care, nutrition, or education, any leaflet, handbill or similar instrument wherein there is an advertisement of any breastmilk substitutes, infant foods, commercially manufactured complementary foods or any accessories thereof; for the purposes of promotion of sale of any breast-milk substitutes, infant foods, commercially manufactured complementary foods or any accessories; to offer or propose to offer any person any gift, discount coupon, price reduction or any other material free of cost; to offer or give any financial or other benefits to any person or any officer or staff of any health care centre or any health worker for receiving any higher education or engaging in any research, in addition to, attending or participating in any seminar, conference, symposium, workshop, training, scientific meeting, education tour or international conference organized or sponsored by the manufacturer thereof; to use any health care centre or any medicine selling centre; to organize any competition or function for or to render any other assistance to, children; to make direct contact with or to offer an alluring proposal to any pregnant woman, lactating mother or mother of children; during the publicity of any commodity, particularly child commodity such as: diaper, clothes, toy, doll, cosmetics, toiletries, etc, to distribute any leaflet or gift relating to any breast-milk substitutes, infant foods, commercially manufactured complementary foods or any accessories; to donate or distribute, among the organizations or rescue shelters that are engaged in saving or reducing risk of children below five years of age or pregnant woman or newly delivered woman who are affected or endangered by natural calamity of any breast-milk substitutes, infant foods, commercially manufactured complementary foods or any accessories thereof. If anyone contravenes any provision of this Act, such contravention shall constitute an offence, and shall be punished with imprisonment which may extent to maximum 3 (three) years or with fine which may extend to maximum 5,00,000 (five lacs) or with both; if a child becomes ill or dies from the use of any breast-milk substitute, infant foods, commercially manufactured complementary foods or of any accessories thereof, it shall constitute a punishable offence under this Act, and for that, the company shall be punished with 10 (ten) years of imprisonment or with fine which may extend to maximum $50,00,000$ (fifty lacs) or with both. For lodging a complaint, conducting an investigation, holding a trial and disposing an appeal in respect of an offence under this Act, the provisions of the Criminal Code shall be applicable. As a Bangladeshi citizen we should all be bided with this law and we doctors should not go into conflict of interest. [ J Shaheed Suhrawar dy Med Coll 2013;5(2):75-76]

\section{References}

1. World Health Organization, International Code of Marketing of BreastMilk Substitutes 1981.

2. Bangladesh Government, Breast milks Substitutes, Infant Foods, Commercially Manufactured Complementary Foods and the Accessories Thereof (Regulation of Marketing) Act, 2013. 